\title{
MicroRNA-200b inhibits pituitary tumor cell proliferation and invasion by targeting PKC $\alpha$
}

\author{
YUANCHUAN WANG* ${ }^{*}$ XIAOHONG YIN*, LONG ZHAO, SHUN LI, \\ JIE DUAN, RENZHAO KUANG and JUNWEI DUAN
}

Department of Neurosurgery, Affiliated Hospital of North Sichuan Medical College, Nanchong, Sichuan 637000, P.R. China

Received August 31, 2015; Accepted January 13, 2017

DOI: $10.3892 /$ etm.2017.4681

\begin{abstract}
The present study aimed to investigate the expression of miR-200b and protein kinase $\mathrm{C} \alpha(\mathrm{PKC} \alpha)$ in pituitary tumors and to determine whether miR-200b may inhibit proliferation and invasion of pituitary tumor cells. The regulation of PKC $\alpha$ expression was targeted in order to find novel targets for the treatment of pituitary tumors. In total, 53 pituitary tumor tissue samples were collected; these included 28 cases of invasive pituitary tumors and 25 cases of non-invasive tumors, in addition to 5 normal pituitaries. The expression level of miR-200b in the pituitary tumor tissue was detected by quantitative polymerase chain reaction (qPCR) and the expression of PKC $\alpha$ protein was detected by immunohistochemistry. A PKC $\alpha$ 3'untranslated region (UTR) luciferase vector was constructed and a dual luciferase reporter gene assay was employed in order to examine the effect of miR-200b on the PKC $\alpha$ 3'UTR luciferase activity. AtT-20 cells were transfected with miR-200b mimics, PKC $\alpha$ siRNA and miR-200b mimics $+\mathrm{PKC} \alpha$, and the changes in cellular proliferation, invasion and apoptosis were observed via MTT, Transwell assay and flow cytometric analysis. Furthermore, PKC $\alpha$ mRNA expression was determined by qPCR, and Western blotting was performed to detect the expression of PKC $\alpha$ protein. miR-200b revealed downregulation in invasive pituitary tumor tissue, and the expression level was significantly down-regulated compared with normal and non-invasive pituitary tumor tissue $(\mathrm{P}<0.01)$. In addition, the positive rate of $\mathrm{PKC} \alpha$ protein expression in invasive pituitary tumor tissues was significantly higher than in normal and non-invasive tissues $(\mathrm{P}<0.01)$. PKC $\alpha$ protein levels are inversely correlated with miR-200b levels in invasive pituitary tumor tissues $(r=-0.436$,
\end{abstract}

Correspondence to: Dr Yuanchuan Wang, Department of Neurosurgery, Affiliated Hospital of North Sichuan Medical College, 63 Wenhua Road, Nanchong, Sichuan 637000, P.R. China E-mail: drwangyc@126.com

*Contributed equally

Key words: pituitary tumor, miR-200b, protein kinase C-alpha, cell proliferation, invasion, apoptosis, AtT-20 cells, invasive pituitary
$\mathrm{P}=0.021)$. The dual luciferase reporter gene assay revealed that miR-200b could specifically bind to the 3'UTR of PKC $\alpha$ and significantly inhibit the luciferase activity by $39 \%(\mathrm{P}<0.01)$. Upregulation of miR-200b or downregulation of PKC $\alpha$ could suppress cell proliferation and invasion, and increase apoptosis of AtT-20 cells. It was revealed that PKC $\alpha$ siRNA could suppress both proliferation and invasion of AtT-20 cells and partially simulate the function of miR-200b. Expression of PKC $\alpha$ mRNA and protein decreased significantly in AtT-20 cells overexpressing miR-200b. Additionally, miR-200b was significantly down-regulated in invasive pituitary tumor tissue and inversely correlated with PKC $\alpha$ protein levels. In conclusion, miR-200b inhibited proliferation and invasiveness and promoted the apoptosis of pituitary tumor cells by targeting PKC $\alpha$. The observations of the present study indicate that miR-200b and PKC $\alpha$ may serve as promising therapeutic targets for invasive pituitary tumors.

\section{Introduction}

Pituitary adenomas generally account for $25 \%$ of intracranial tumors and can be divided into functioning and non-functioning pituitary adenomas. Non-functioning pituitary adenomas are not associated with sufficient hormone secretion, whereas functioning pituitary tumors are associated with excess pituitary hormones (prolactin, growth hormone, adrenocorticotropic hormone and thyroid-stimulating hormone) $(1,2)$. The majority of pituitary tumors are benign; however, 5 to $35 \%$ of tumors are locally invasive and are therefore difficult to treat (1). Several genetic syndromes, including Carney complex and McCune-Albright syndrome, are known to be associated with the development of pituitary adenomas, but for sporadic adenomas the molecular pathology remains poorly understood (3-5). Invasive pituitary tumors have a high mortality rate because they are not easily cured by surgical, medical and radiation therapies, which tend to be partially effective or wholly ineffective (6). Therefore, there is an urgent requirement to develop early diagnostic biomarkers and to demonstrate the molecular mechanism of invasive pituitary tumors in order to improve disease management.

MicroRNAs (miRNAs) are a large family of short non-protein-coding RNA molecules of 22 nucleotides in length, functioning as key regulators of gene expression by binding to the 3'untranslated region (3'UTR) of their target 
mRNAs (7). In total, $50 \%$ of miRNAs are located in chromosomal fragile genomic sites (8), emphasizing a key role of miRNAs in tumor pathogenesis. Emerging evidence demonstrates that aberrant miRNA expression is linked to cancer, including pituitary tumors (9-12). A previous study of treatment with the dopamine agonist, miR-200a, demonstrated a significantly different expression between treated and untreated nonfunctioning pituitary adenomas (13). The human miR-200 family includes five members divided into two groups: The miR-200b/-200a/-429 group located on chromosome 1 and the miR-200c/-141 group located on chromosome 12 (14). miR-200 are potential inhibitors of epithelial-to-mesenchymal transition, which is associated with promoting tumor cell invasion and proliferation (15-18). However, the potential roles of miR-200b in pituitary tumorigenesis are less known. The present study therefore aimed to demonstrate the potential function and regulatory mechanism of miR-200b in pituitary tumorigenesis.

In the current study, miR-200b was investigated in both invasive pituitary tumor tissues and pituitary tumor cell lines, and cell proliferation and invasion in response to this were also examined. A direct target of miR-200b, protein kinase $\alpha(\mathrm{PKC} \alpha)$, is important in regulating cell migration and cancer metastasis $(19,20)$, and it was therefore studied in the present research. The current study may therefore promote the development of an effective therapeutic strategy for pituitary tumors.

\section{Materials and methods}

Patients and tissue samples. Specimens were obtained from the Department of Neurosurgery of the Affiliated Hospital of North Sichuan Medical College between November 2013 and December 2014 in patients undergoing surgery. In total, 53 patients with pituitary tumors, including 28 cases of invasive pituitary tumors and 25 non-invasive cases were included. Previous conventional or gamma knife radiotherapy was not performed in any of the patients. The diagnosis of invasive pituitary tumors was based on the Hardy-Wilson and Vezina (21) and Knosp et al (22) grading and staging criteria. In total, 5 normal pituitary glands were obtained from autopsy ( $2 \mathrm{~h}$ post mortem) from patients with no history of endocrine abnormality. Their families signed the informed consent. None of these cases had a recognized pituitary disease, and pituitaries exhibited a normal gland appearance. Tissue samples were immediately frozen in liquid nitrogen at the time of surgery and stored at $-70^{\circ} \mathrm{C}$ until RNA was extracted. A section of the tumor tissue was fixed in $10 \%$ formalin, paraffin-embedded and used for immunohistochemistry. Finally, informed consent for the present study was obtained from all patients, and the present study was approved by the Research Ethics Committee of Xiangya Hospital (Xiangya, China).

Reverse transcription-quantitative polymerase chain reaction (RT-qPCR). The total RNA was extracted and purified using miRNeasy mini kit (Qiagen, Inc., Valencia, CA, USA) and quantified using a NanoDrop ND-2000 (Nanodrop; Thermo Fisher Scientific, Inc., Wilmington, DE, USA). The $\mathrm{OD}_{260} / \mathrm{OD}_{280}$ ratio of RNA was between $1.7-2.1$, indicating a high purity. The cDNA template was acquired by reverse transcription (RT). RNA was extracted from $~ 100$ mg pituitary gland tissue using the TRI reagent ${ }^{\circledR}$ (Sigma-Aldrich; Merck $\mathrm{KGaG}$, Darmstadt, Germany) following the manufacturer's protocol. RNA was reverse transcribed using AMV Reverse Transcriptase (Promega Corporation, Madison, WI, USA) in a total volume of $20 \mu \mathrm{l}$, with $1 \mu \mathrm{g}$ pituitary RNA, 30 pmol oligo (dT) 15, $4 \mu 1$ 5xAMV reverse transcriptase buffer, $2 \mu 1$ deoxynucleotide triphosphate (dNTP) mix, 20 units ribonuclease inhibitor and 15 units of AMV reverse transcriptase. The RT reaction (RNA concentration is $2 \mu \mathrm{g} / \mathrm{ml}$ ) was conducted using a Tetrad2 Peltier Thermal Cycler (BioRad Laboratories, Ltd., Hercules, CA, USA) under the following conditions: $16^{\circ} \mathrm{C}$ for $30 \mathrm{~min}, 42^{\circ} \mathrm{C}$ for $30 \mathrm{~min}, 85^{\circ} \mathrm{C}$ for $5 \mathrm{~min}$ and hold at $4^{\circ} \mathrm{C}$. RT products were stored at $-20^{\circ} \mathrm{C}$ prior to RT-qPCR. qPCR was performed using $25 \mu \mathrm{l}$ volumes on 96-well plates with a reaction buffer containing 1xTaqMan Universal PCR Master Mix (Thermo Fisher Scientific, Inc., Waltham, MA, USA), 3 mM Mn(OAc) $)_{2}, 200 \mu \mathrm{M}$ dNTPs, 1x25 U AmpliTaq Gold polymerase (\#4398823, Thermo Fisher Scientific, Inc., Waltham, MA, USA), 1x25 U AmpErase UNG (\#N8080096, Thermo Fisher Scientific, Inc.), 100-200 nmol TaqMan probe (\#4316034, Thermo Fisher Scientific, Inc.) and 900 nmol primers (sequences presented in Table I). U6 snRNA served as an endogenous control and was used to normalize the expression levels of miR-200b. The relative expression of miR-200b was calculated using the $2^{-\Delta \Delta \mathrm{Cq}}$ method and the experiment was repeated 3 times (23). qPCR was performed using an ABI7500 qPCR instrument (Applied Biosystems; Thermo Fisher Scientific, Inc.) under the following conditions: $95^{\circ} \mathrm{C}$ for $10 \mathrm{~min}$, followed by 40 cycles of $95^{\circ} \mathrm{C}$ for $15 \mathrm{sec}, 60^{\circ} \mathrm{C}$ for $1 \mathrm{~min}$ and hold at $4^{\circ} \mathrm{C}$. Raw data were analysed with the Relative Quantification Software version 2.2.3 (Applied Biosystems, Thermo Fisher Scientific, Inc., Waltham, MA, USA).

Immunohistochemistry to detect the expression of PKC $\alpha$. The expression of PKC $\alpha$ protein in the pituitary tumor tissue was detected by the universal PV-9000 two-step method $(24,25)$. Briefly, formalin-fixed paraffin-embedded tissues from 53 pituitary tumors and 5 normal pituitary tissues were cut into 4- $\mu \mathrm{m}$ slices. Deparaffinization, graded ethanol dehydration, antigen retrieval and $3 \%$ hydrogen peroxide were used to block endogenous peroxidase. Rabbit anti-human PKC $\alpha$ monoclonal antibody (catalogue no. bs-3531R, 1:200, Bioss, Beijng, China) were added and incubated at $4^{\circ} \mathrm{C}$ overnight. Mouse anti-rabbit IgG/horseradish peroxidase (HRP) antibody (catalogue no. bs-0295M-HRP, 1:800, Bioss, Beijng, China) was then applied and incubated for $30 \mathrm{~min}$ at room temperature. Staining was performed using diaminobenzidine (DAB) and slices were counterstained using hematoxylin (Sigma-Aldrich; Merck $\mathrm{KGaG}$ ) before mounting.

The following integral calculation method for PKC $\alpha$ was used: 5 high-power fields of view (magnification, x400) were randomly selected in each slice with 100 cells per field, and the scores were calculated as the product of staining intensity (3, brown; 2, yellow; 1, light yellow and 0, colorless) and the percentage of positive cells $(4,>75 \% ; 3,51-75 \% ; 2,26-50 \%$; $1,6-25 \%$ and $0,<5 \%$ ). Evaluation values are represented by a product of two types of scores according to the integral level: Negative (-), 0 points; weakly positive (+), 1-4 points; 
Table I. The sequences of primers used for reverse transcription-quantitative polymerase chain reaction.

\begin{tabular}{lll}
\hline cDNA & \multicolumn{1}{c}{ Forward Primer $\left(5^{\prime}-3^{\prime}\right)$} & \multicolumn{1}{c}{ Reverse Primer (5'-3') } \\
\hline MiR-200b & TAATACTGCCTGGTAATGATGA & ATCATTACCAGGCAGTATAAAT \\
PKC $\alpha$ & TGCTGACTTTGGGATGTG & TGTTTGTTCTCGCTGGTG \\
GAPDH & ACAACTTTGGTATCGTGGAAGG & GCCATCACGCCACAGTTC \\
U6 & CTCGCTTCGGCAGCACA & AACGCTTCACGAATTTGCGT
\end{tabular}

PKC $\alpha$, protein kinase C $\alpha$; GAPDH, glyceraldehyde 3-phosphate dehydrogenase.

and strongly positive $(++),>4$ points. The slides were evaluated independently by two pathologists blinded to treatment groups.

Luciferase assay. DNA extraction was performed using the TIANamp Genomic DNA kit (Tiangen Biotech, Co. Ltd., Beijjng, China) according to the manufacturer's instructions. Wild-type and mutant-type PKCa 3'UTR luciferase reporter vectors (Shanghai GenePharma Co., Ltd., Shanghai, China) were constructed. MiR-200b mimics (catalogue no. B01001, Shanghai GenePharma Co., Ltd.) or negative controls (NC, catalogue no. B04001, Shanghai GenePharma Co., Ltd.) were co-transfected with a constructed wild- or mutant-type luciferase reporter vector into mouse pituitary tumor AtT-20 cells (purchased from the Shanghai Institute of Biochemistry and Cell Biology, Shanghai, China), as described in the subsequent section. A pRL-TK control vector (catalogue no. E2241, Promega Corporation) served as a control. Following $48 \mathrm{~h}$ of transfection, the activity of luciferase was measured using a Dual-Luciferase Reporter Assay System (E1910; Promega Corporation, Madison, WI, USA) according to the manufacturer's instructions. Furthermore, the Renilla luciferase activity was used for normalization. The cell transfection was conducted using Lipofectamine 2000 (Invitrogen, Thermo Fisher Scientific, Inc.).

Cell culture and cell transfection. All cells were grown in RPMI 1640 medium supplemented with 10\% fetal bovine serum (FBS, Gibco, Thermo Fisher Scientific, Inc.), and incubated at $37^{\circ} \mathrm{C}$ in a humidified atmosphere of $5 \% \mathrm{CO}_{2}$. Cultured cells were grown in monolayers and the cell confluency was expected to reach $90 \%$ when passaged. The old media were discarded during passaging; PBS was used to wash the cells, $0.25 \%$ trypsin digestion was performed and trypsin was neutralized with RPMI 1640 medium (Gibco; Thermo Fisher Scientific, Inc.) upon detachment of the monolayer. Next, cells were suspended in RPMI 1640 medium supplemented with $10 \%$ fetal bovine serum (FBS) to obtain single cell suspensions, and the cells were routinely passaged.

For transfection, the treatment groups were as follows: No transfection (control), $\mathrm{NC}$ of miR-200b mimics negative control (NC), miR-200b mimics (mimics), PKC $\alpha$ siRNA (siRNA) and miR-200b mimics + PKC $\alpha$ (mix) groups. The cells were inoculated into a 50-ml culture bottle, and grown in complete medium (RPMI 1640 medium supplemented with 10\% FBS; Gibco; Thermo Fisher Scientific, Inc.) to a density of $30-50 \%$.
The AtT-20 cells were transfected using Lipofectamine 2000 (Invitrogen; Thermo Fisher Scientific, Inc.) in serum-free RPMI 1640 medium. Transfected cells were incubated in RPMI 1640 medium supplemented with $10 \% \mathrm{FBS}$ at $37^{\circ} \mathrm{C}$ in a humidified atmosphere of $5 \% \mathrm{CO}_{2}$. The RPMI 1640 medium supplemented with $10 \%$ FBS was replaced after 6-8 $\mathrm{h}$ and the culture was continued.

MTT assay. MTT assays were used to measure cell proliferation. PBS was used for two washes, and transfected cells were cultured to a confluency of $80 \%$. Cells were subjected to trypsin digestion and resuspended into single cell suspensions and counted using a hemocytometer. Transfected AtT-20 cells were seeded in 96-well plates at a density of 3-6x $10^{3}$ cells/well and cultured in $200 \mu$ of RPMI 1640 medium supplemented with $10 \%$ FBS. The culture was repeated in six wells and incubated at $37^{\circ} \mathrm{C}$ in a humidified atmosphere of $5 \% \mathrm{CO}_{2}$. RPMI 1640 medium was added to unseeded cell wells and was determined to represent ' 0 '. The cells were examined following incubation for 24, 48 and $72 \mathrm{~h}$. A volume of $20 \mu \mathrm{l}$ MTT ( $5 \mu \mathrm{g} / \mathrm{ml}$; Sigma-Aldrich; Merck KGaA) was added to each well and the cells were incubated at $37^{\circ} \mathrm{C}$ in a humidified atmosphere of $5 \% \mathrm{CO}_{2}$ for $4 \mathrm{~h}$. The cell culture was terminated by replacing the medium with new RPMI 1640 medium. Dimethyl sulfoxide $(150 \mu \mathrm{l})$ was added to each well and shaken for $10 \mathrm{~min}$ in order to dissolve the formazan crystals. The absorbance was then measured using a microplate reader (SpectraMAX Plus, Molecular Devices, LLC, Sunnyvale, CA, USA) at a wavelength of $490 \mathrm{~nm}$. An MTT curve was drawn using SPSS 19.0 software (IBM SPSS, Armonk, NY, USA) with an absorbance value set to the vertical axis and the interval was set to abscissa. This experiment was repeated three times.

Transwell cell invasion assay. Matrigel (BD Biosciences, San Jose, CA, USA) was diluted in serum-free RPMI 1640 medium into a 1:3 ratio, and this was followed by an overnight incubation at $4^{\circ} \mathrm{C}$. Diluted Matrigel was added to each Transwell chamber (BD Biosciences, Franklin Lakes, NJ, USA), ensuring appropriate spreading of Matrigel. At $48 \mathrm{~h}$ after transfection, cells were plated in Transwell chambers and $0.5 \mathrm{ml}$ RPMI 1640 medium supplemented with $10 \%$ fetal bovine serum was added in the lower chamber as a chemoattractant. The membrane was then stained using $0.1 \%$ crystal violate staining solution. The number of cells traversing the Matrigel in each group was used as an evaluation index of their invasive ability. This experiment was repeated 3 times. 
Flow cytometric analysis of apoptosis. The apoptosis rate of AtT-20 cells was measured via flow cytometric analysis using an Annexin V-fluorescein isothiocyanate (FITC) and propidium iodide (PI) apoptosis detection kit (BD Biosciences). Briefly, $48 \mathrm{~h}$ after transfection, cells were harvested and were washed twice in cold PBS. The cells were resuspended in binding buffer at a concentration of $0.5-1 \times 10^{6}$ cells $/ \mathrm{ml}$. This suspension $(100 \mu \mathrm{l})$ was then incubated with $5 \mu \mathrm{l}$ of AnnexinV-FITC and PI for $15 \mathrm{~min}$ at room temperature and in the dark. Following the addition of $400 \mu \mathrm{l}$ binding buffer to each tube, the cells were analyzed with a FC 500 MCL/MPL flow cytometer (Beckman Coulter, Inc., Brea, CA, USA). This experiment was repeated 3 times.

qPCR to detect the expression of PKC $\alpha \mathrm{mRNA}$. The total RNA of cells was extracted using an RNA isolation reagent (TRIzol, catalogue no. 15596026, Ambion ${ }^{\circledR}$, Thermo Fisher Scientific, Inc.) according to the manufacturer's instructions, and was reverse transcribed using the RevertAid First Strand cDNA Synthesis kit (catalogue no. K1622, Fermentas; Thermo Fisher Scientific, Inc., Pittsburgh, PA, USA). In a total volume of $20 \mu \mathrm{l}$, with $1 \mu \mathrm{g}$ PKC $\alpha$ mRNA, 30 pmol oligo (dT) 15, $4 \mu 1$ 5x reaction buffer, $2 \mu 1$ deoxynucleotide triphosphate (dNTP) mix, 20 units RiboLock RNase inhibitor and 15 units of RevertAid reverse transcriptase. The RT reaction was conducted using a Tetrad2 Peltier Thermal Cycler (BioRad Laboratories) under the following conditions: $16^{\circ} \mathrm{C}$ for $30 \mathrm{~min}, 42^{\circ} \mathrm{C}$ for $30 \mathrm{~min}, 85^{\circ} \mathrm{C}$ for $5 \mathrm{~min}$ and hold at $4^{\circ} \mathrm{C}$. The concentration of the RNA sample is $2 \mu \mathrm{g} / \mu \mathrm{l}$. RT products were stored at $-20^{\circ} \mathrm{C}$ prior to RT-qPCR. qPCR was performed according to the manufacturer's instructions of Maxima SYBR Green/Fluorescein qPCR Master Mix (2X) kit (\#K0242, Fermentas; Thermo Fisher Scientific, Inc.). The following primers were used for amplification of PKC $\alpha$ : sense, 5'-TGC TGACTTTGGGATGTG-3' and antisense, 5'-TGTTTGTTC TCGCTGGTG-3' (Invitrogen; Thermo Fisher Scientific, Inc.). qPCR was carried out in $20 \mu \mathrm{l}$ volumes on 96-well plates with a reaction buffer containing 1x Maxima SYBR Green/Fluorescein qPCR Master Mix (2X; \#K0242, Thermo Fisher Scientific, Inc.), 200 mM dNTPs, 1x25 U Maxima Hot Start Taq DNA Polymerase (\#EP0601, Thermo Fisher Scientific, Inc.), 2-5 mM MgCl $2,100-200$ nmol SYBR Green I (\#S7563, Thermo Fisher Scientific, Inc.) and $0.5 \mu \mathrm{M}$ primers (sequences presented in Table I). This reaction included a $30 \mathrm{sec}$ denaturation, followed by 40 cycles of $95^{\circ} \mathrm{C}$ for $15 \mathrm{sec}$, $55^{\circ} \mathrm{C}$ annealing for $5 \mathrm{sec}$ and $72^{\circ} \mathrm{C}$ extension for $5 \mathrm{sec}$. U6 snRNA served as an endogenous control for normalization of the expression levels of PKC $\alpha$. The relative expression quantity of PKC $\alpha$ was calculated using the $2^{-\Delta \Delta C q}$ method (23). This experiment was repeated three times.

Western blot analysis to detect PKC $\alpha$ protein expression. Cellular proteins were extracted $48 \mathrm{~h}$ after transfection using the RIPA Lysis Buffer (\#P0013C, Beyotime, Shanghai, China), and protein concentrations were determined with a bicinchoninic acid (BCA) kit (catalogue no. P0011, Beyotime Institute of Biotechnology, Shanghai, China). The cellular protein extraction was completed as follows: RPMI 1640 culture medium supplemented with $10 \%$ fetal bovine serum (FBS; Gibco, Thermo Fisher Scientific, Inc.) was carefully discarded and the cells were washed twice with cold PBS. Subsequently $1 \mathrm{ml}$ cold RIPA buffer was added to each flask $\left(75 \mathrm{~m}^{2}\right)$, and the flask was incubated on ice for $5 \mathrm{~min}$. The lysate was then gathered using a cell scraper, collected and transferred to a centrifuge tube. The lysate was then centrifuged at $14,000 \times \mathrm{g}$ at $4^{\circ} \mathrm{C}$ for $15 \mathrm{~min}$ to pellet the cell debris. The supernatant was then transferred to a new tube. Equal amounts of proteins from each group were loaded and separated by $8 \%$ sodium dodecyl sulfate-polyacrylamide gel electrophoresis (SDS-PAGE), transferred onto polyvinylidene fluoride (PVDF) membranes and blocked with $5 \%$ non-fat milk. Membranes were incubated with antibodies against PKC $\alpha$ (catalogue no. ab32376, 1:2,000, Sigma-Aldrich; Merck KGaG) and glyceraldehyde 3-phosphate dehydrogenase (GAPDH; catalogue no. ab181602, 1:10,000, Sigma-Aldrich; Merck KGaG) at $4^{\circ} \mathrm{C}$ overnight. Membranes were then washed three times with Tris-buffered saline and Tween-20 (TBST; $10 \mathrm{~min}$ each) and incubated with HRP-conjugated secondary antibodies for $1 \mathrm{~h}$ at room temperature. Membranes were then washed with TBST three times (10 min each) and signal detection was performed using Super ECL Plus Detection Reagent (Applygen Technologies Inc., Beijing, China). This experiment was performed three times.

Statistical analysis. All experiments were repeated at least three times and all statistical analyses were performed using SPSS 19.0 software (SPSS, Inc., Chicago, IL, USA). The statistical analyses for the significance of differences in numerical data (mean \pm standard deviation) were performed by analysis of variance. Differences between the two groups were analyzed by unpaired t-tests. The results of immunohistochemistry for the PKC $\alpha$ protein were analyzed by the rank-sum test. The association between the expression levels of miR-200b and PKC $\alpha$ protein was analyzed by Spearman rank correlation. $\mathrm{P}<0.05$ was considered to indicate a statistically significant difference.

\section{Results}

MiR-200b and PKCa protein expression in pituitary tumor clinical specimens. qPCR was used to evaluate the expression level of miR-200b in 28 cases of invasive pituitary tumors, 25 cases of non-invasive and 5 normal pituitaries (Fig. 1A). The results demonstrated that miR-200b expression in invasive pituitary tumor tissues was significantly lower than in non-invasive and normal tissues $(\mathrm{P}<0.01)$. However, there was no significant difference in miR-200b expression levels between non-invasive and normal tissues $(\mathrm{P}>0.05)$. In the normal pituitary and non-invasive pituitary tumors, $\mathrm{PKC} \alpha$ demonstrated only mild expression in the cell cytoplasm (Fig. 1B); while in the invasive pituitary tumors, PKC $\alpha$ was mainly located in the cell cytoplasm and extracellular matrix. Expression of PKC $\alpha$ was distributed in an uneven manner (Fig. 1B). Expression of PKC $\alpha$ protein in invasive pituitary tumor tissues was significantly higher than in normal and non-invasive tissues $(\mathrm{P}<0.01$; Table II). Spearman correlation analysis indicated a negative correlation between the miR-200b level with PKC $\alpha$ protein levels in invasive pituitary tumor tissues $(r=-0.436 ; P=0.021)$, but there was no significant 


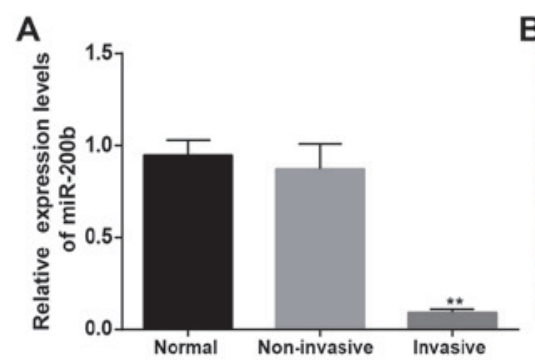

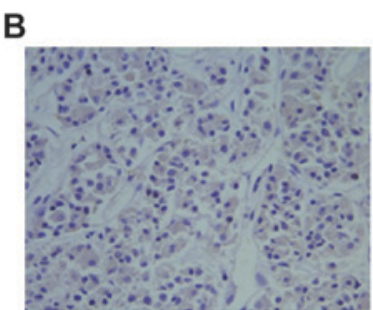

Normal

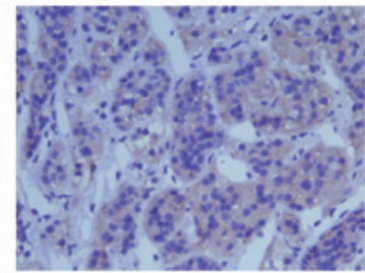

Non-invasive

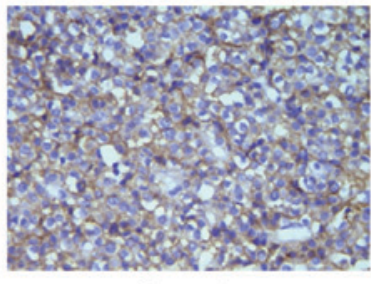

Invasive

Figure 1. Relative expression of miR-200b and PKC $\alpha$ distribution in pituitaries. (A) Relative expression of miR-200b in invasion pituitaries were significantly lower than that in normal and non-invasive pituitaries. Data were presented as mean \pm standard deviation, ${ }^{* *} \mathrm{P}<0.01$ vs. normal. (B) Immunohistochemical staining results demonstrating PKC $\alpha$ expression in normal, non-invasive and invasive pituitaries. The brown color indicates the positive staining of PKC $\alpha$. PKC $\alpha$ expression is significantly overexpressed in invasive pituitaries, and there is no significant difference of PKC $\alpha$ expression between the normal and the non-invasive pituitaries. Staining was performed using diaminobenzidine and slices were counterstained using hematoxylin. Magnification x400. miR, micro RNA; PKC $\alpha$ : protein kinase $\mathrm{C} \alpha$.

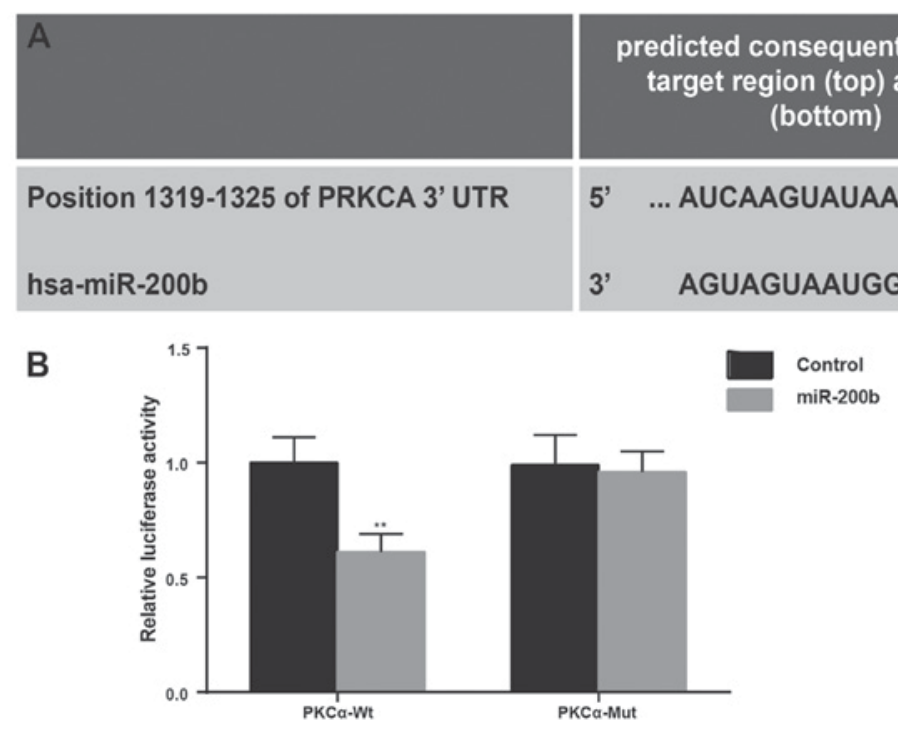

Figure 2. PKC $\alpha$ and miR-200b sequence scheme along with the dual luciferase reporer gene assay results. (A) Base pairing between the seed sequence of mature miR-200b and the 3'UTR of PKC $\alpha$ mRNA. (B) Relative luciferase activities of cells in PKC $\alpha$-Wt and PKC $\alpha$-Mut 3'UTR groups in response to miR-200b transfection. Cells transfected with PKC $\alpha-W t$ and miR-200b mimics demonstrated substantially decreased luciferase activity than those transfected with PKC $\alpha$-Wt and control. "* P<0.01 vs. control. miR, micro RNA; UTR, untranslated region; PKC $\alpha$, protein kinase C $\alpha$; Wt, wild type; Mut, mutated type.

Table II. Expression level of PKC $\alpha$ protein in pituitary tissues.

\begin{tabular}{lrrrrrrr}
\hline & & \multicolumn{3}{c}{ PKC $\alpha$} & & \\
\cline { 3 - 5 } Group & No. & - & + & ++ & $\chi^{2}$ & P-value \\
\hline Control & 5 & 4 & 1 & 0 & - & - \\
Non-invasive & 25 & 6 & 7 & 12 & 6.42 & $<0.01^{\text {a }}$ \\
Invasive & 28 & 0 & 2 & 26 & 27.81 & $<0.01^{\text {a }}$ \\
\hline
\end{tabular}

$\mathrm{PKC} \alpha$, protein kinase $\mathrm{C} \alpha .{ }^{\mathrm{a}} \mathrm{P}<0.01$ vs. control.

correlation between miR-200b and PKCa in normal and non-invasive tissues.

Targeting PKCa by miR-200b. A putative conserved binding site for miR-200b at nucleotide position 1319-1325 of human PKC $\alpha$ 3'UTR was predicted using Targetscan (http://www .targetscan.org/vert_71/) and matching base pairing was observed between the seed sequence of mature miR-200b and the 3'UTR of PKC $\alpha$ mRNA (Fig. 2A). Dual luciferase reporter gene assays revealed that re-expressing miR-200b in AtT-20 cells significantly inhibited the luciferase activity of PKC $\alpha$ wild-type 3'UTR following by a downregulation of $39 \%(\mathrm{P}<0.01)$. However, no significant effect on the PKC $\alpha$ mutant-type 3'UTR luciferase activity was observed (Fig. 2B). Collectively, these observations indicate that PKC $\alpha$ is a target of miR-200b.

Pituitary tumor cell proliferation was detected by the MTT assay. MTT assays were used to assess cell proliferation. As shown in Fig. 3, MTT assays demonstrated decreased proliferation of AtT-20 cells transfected with miR-200b mimics and PKC $\alpha$ siRNA for $48 \mathrm{~h}$ compared with the control and $\mathrm{NC}$ groups $(\mathrm{P}<0.05)$, and the difference is more evident with the extension of time. The number of control and $\mathrm{NC}$ group cells were not significantly different at any time point 
A

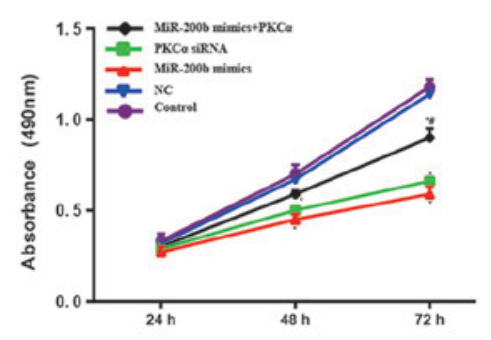

B

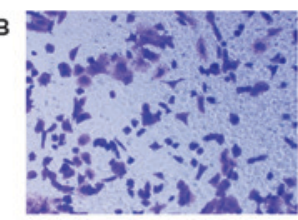

Control

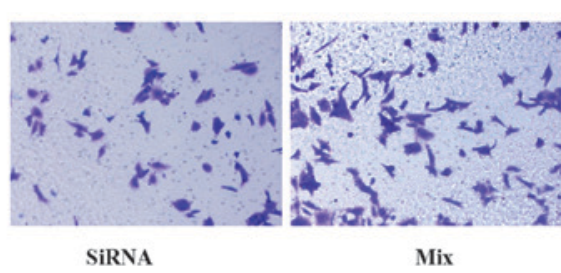

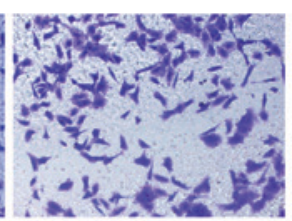

NC

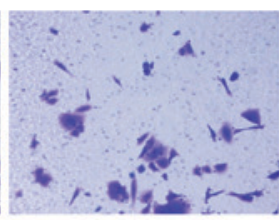

Mimics

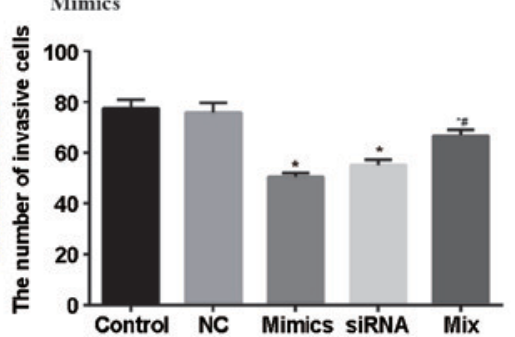

Figure 3. Proliferation rate and invasiveness of AtT-20 cells transfected in different groups. (A) No significant difference was observed between the control and NC groups in terms of cell proliferation rate. There was significant difference of the mimics and siRNA groups in terms of AtT-20 cell proliferation rate from the control and $\mathrm{NC}$ groups. Compared with the control and $\mathrm{NC}$ groups, the cell proliferation rate of the mix group was also significantly elevated. (B) Transfection of miR-200b mimics or PKCa siRNA led to the decrease of cell invasion, whereas the simultaneous transfection of miR-200b mimics and $\mathrm{PKC} \alpha-W t$ led to significant alteration of cell invasiveness compared with the control. The membrane was then stained using $0.1 \%$ crystal violet. Magnification x10. ${ }^{~} \mathrm{P}<0.05$, vs. control and NC groups; ${ }^{\#} \mathrm{P}<0.05$, vs. mimics group. Data are presented as mean \pm standard deviation. NC, negative control; siRNA, short interfering RNA; miR, micro RNA; PKC $\alpha$, protein kinase $\mathrm{C} \alpha$; Wt, wild type; Mut, mutated type.
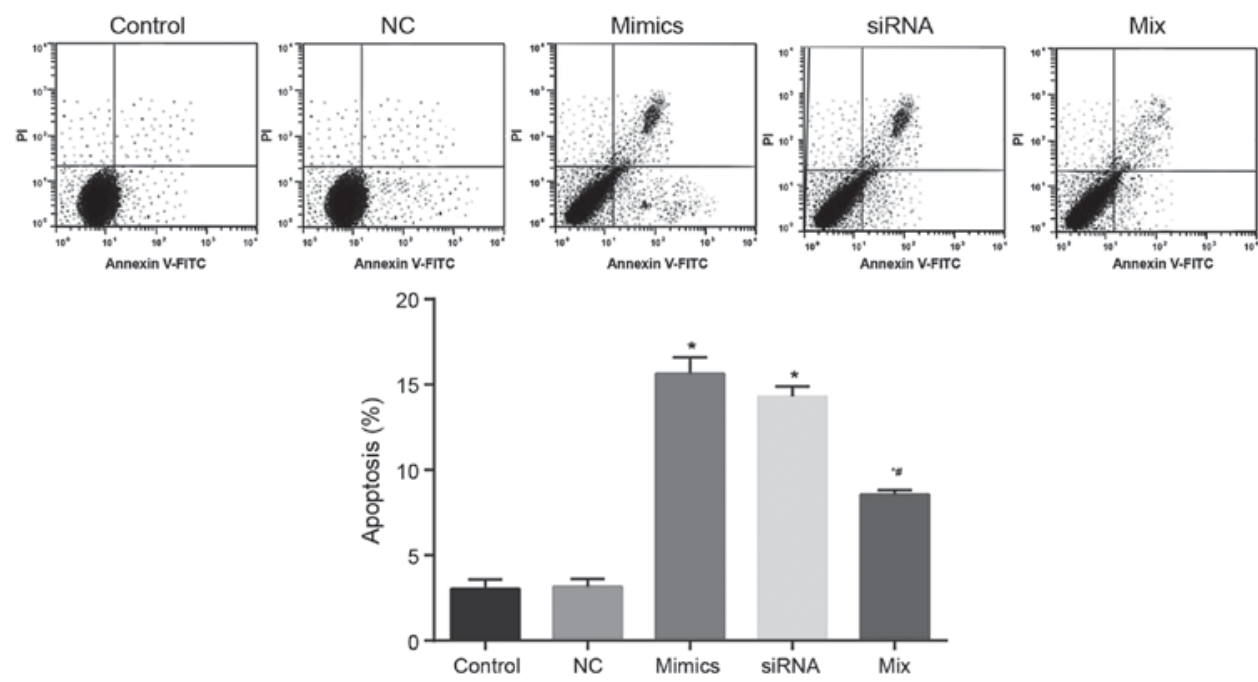

Figure 4. Cell apoptosis following $48 \mathrm{~h}$ transfection. The transfection of miR-200b mimics or PKC $\alpha$ siRNA led to the increase of cell death, whereas the simultaneous transfection of miR-200b mimics and $\mathrm{PKC} \alpha$ led to significant alteration of cell apoptosis compared with the control, NC, mimics or siRNA group. ${ }^{*} \mathrm{P}<0.05$, vs. control and $\mathrm{NC}$ groups; ${ }^{*} \mathrm{P}<0.05$, vs. mimics group. Data are presented as mean \pm standard deviation. $\mathrm{PKC} \alpha$, protein kinase $\mathrm{C} \alpha$; miR, micro RNA; siRNA, short interfering RNA; NC, negative control; FITC, fluorescein isothiocyanate.

recorded $(\mathrm{P}>0.05)$. AtT-20 cell proliferation activity decreased following the transfection of miR-200b mimics, but the addition of PKC $\alpha$ appeared to partially reverse the inhibitory effect of miR-200b on AtT-20 cell proliferation $(\mathrm{P}<0.05)$.

Transwell assay. As shown in Fig. 3, a Transwell Matrigel invasion assay demonstrated that the ability of miR-200b to inhibit cell invasion is non-significantly better than PKC $\alpha$ siRNA, based on number of cells invading in miR-200b mimics (50.5 \pm 1.5$)$ and PKC $\alpha$ siRNA (55.3 \pm 2.0$)$ treatment groups $(\mathrm{P}>0.05)$. However, a significant difference was observed when comparing these groups to the control (77.5 \pm 3.5$)$ and NC $(75.8 \pm 3.8)$ groups $(\mathrm{P}<0.05)$. Furthermore, there was no significant difference between the control and $\mathrm{NC}(\mathrm{P}>0.05)$ groups. The number of cells invading the membrane in the mix group was $66.6 \pm 2.5$, which is significantly different from any other group $(\mathrm{P}<0.05)$. These results indicate that upregulation of miR-200b or downregulation of PKC $\alpha$ can inhibit the invasive ability of AtT-20 cells and PKC $\alpha$ can impair the inhibitory effect of miR-200b on AtT-20 cell invasion.

Apoptosis assay. Cell apoptosis $48 \mathrm{~h}$ after transfection is reported in Fig. 4. Flow cytometry analysis demonstrated that the apoptosis rate of cells in mimics and siRNA groups were $15.63 \pm 0.96$ and $14.29 \pm 0.61$, respectively, and no significant difference was observed between these two groups $(\mathrm{P}>0.05)$. However, the apoptosis rate of these two groups was significantly higher compared with the control $(3.03 \pm 0.54)$ and NC $(3.15 \pm 0.46)$ groups $(\mathrm{P}<0.05)$. The apoptosis rate of the mix group was $8.56 \pm 0.26$, which was significantly different 

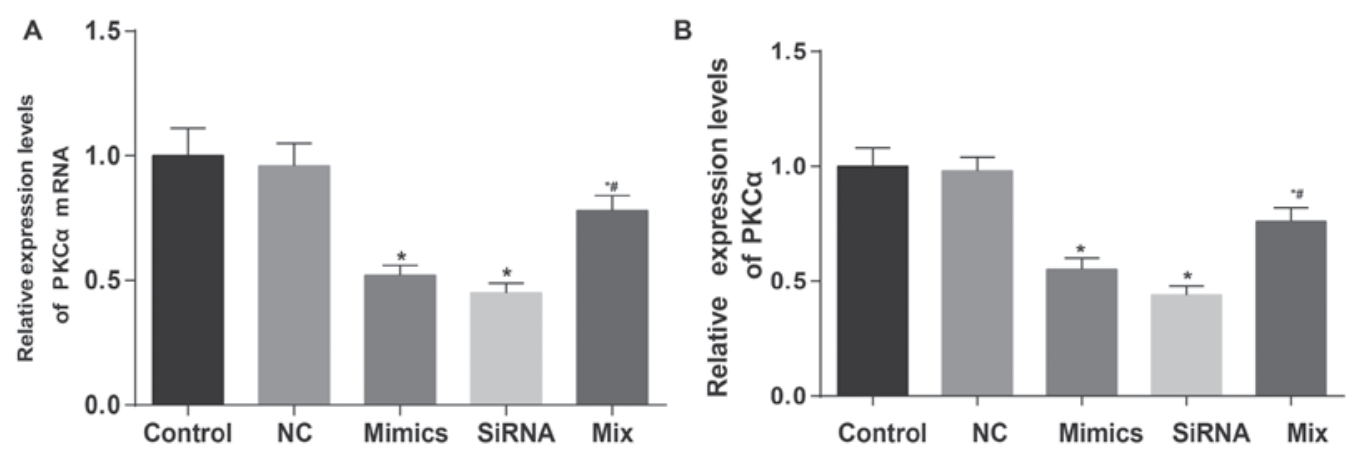

Figure 5. Relative expression level of $P K C \alpha \mathrm{mRNA}$ and protein. (A) MiR-200b mimics and PKC $\alpha$ siRNA significantly downregulated the expression of PKCa mRNA, whereas the simultaneous transfection of miR-200b mimics and PKC $\alpha$ siRNA led to insignificant alteration of PKC $\alpha$ mRNA expression compared with the mimics or the siRNA group. (B) MiR-200b mimics and PKC $\alpha$ siRNA significantly downregulated the expression of PKC $\alpha$ protein, whereas the simultaneous transfection of miR-200b mimics and PKC $\alpha$ led to significant alteration of PKC $\alpha$ expression compared with the other groups. "P<0.05, vs. control and $\mathrm{NC}$ groups; ${ }^{\prime} \mathrm{P}<0.05$, vs. mimics group. Data were presented as mean \pm standard deviation. PKC $\alpha$, protein kinase $\mathrm{C} \alpha$; miR, micro RNA; siRNA, short interfering RNA; NC, negative control.

from any other groups $(\mathrm{P}<0.05)$. These observations indicate that the upregulation of miR-200b or the downregulation of $\mathrm{PKC} \alpha$ can induce the apoptosis of AtT-20 cells and PKC $\alpha$ can partially reverse the effect of miR-200b on AtT-20 cell apoptosis.

MiR-200b and PKC $\alpha$ protein expression in pituitary tumor cell line. qPCR and western blotting analysis results revealed that the expression of PKC $\alpha$ mRNA and protein was significantly decreased $48 \mathrm{~h}$ after transfection with the siRNA and mimics compared with the control and NC groups $(\mathrm{P}<0.05$; Fig. 5). However, there was no significant difference between the control and NC groups ( $\mathrm{P}>0.05)$. Transfection in the mix group with $\mathrm{PKC} \alpha$ could partially recover the expression of PKC $\alpha$ mRNA and protein in AtT-20 cells compared to the miR-200b mimics group. Therefore, miR-200b down-regulated the expression level of PKC $\alpha$ and PKC $\alpha$ siRNA reduced endogenous expression of the PKC $\alpha$ gene. These observations indicated that miR-200b could target the regulation of PKC $\alpha$ gene expression in AtT-20 cells.

\section{Discussion}

MiRNAs are involved in diverse biological processes, including cellular differentiation, proliferation and apoptosis $(26,27)$. These small non-coding RNAs function by regulating the target gene expression and influencing the process of translation (28). Furthermore, miRNAs have been suggested to be important in various types of cancer (28). Although the function of multiple miRNAs remains unknown, the miRNAs have demonstrated varying effects in the etiology of cancer (29). A number of miRNAs act as tumor suppressor factors whereas others work in tumorigenesis (30). Among the miRNAs, the miR-200 family is proven to be directly associated with tumor metastasis and invasiveness (30-32). miR-200b, which is one of the members of the miR-200 family, has also been reported to have abnormal expression in various types of cancer, including bladder cancer and gastric carcinoma $(33,34)$. However, the association between miR-200b and pituitary tumors remains unclear. In the present study, the expression of miR-200b in pituitary tumors was analyzed. The results revealed that the downregulation of miR-200b in invasive pituitary tumors was comparable to the normal pituitary gland and non-invasive pituitary tumors, indicating that miR-200b was of note in pituitary tumors and is correlated with their invasiveness. In addition, the correlation analysis implied that miR-200b was negatively correlated with the expression of PKC $\alpha$, which has a relatively high expression in invasive pituitary tumors. The luciferase reporter assay demonstrated that miR-200b directly targets the PKC $\alpha$ gene by interacting with the 3'UTR in PKC $\alpha$ mRNA. Furthermore, through in vitro assays, transfection with PKC $\alpha$ siRNA and miR-200b mimics was shown to be capable of causing reduced invasiveness and proliferation in AtT-20 cells and promoting cell apoptosis. Furthermore, the low expression of miR-200b contributes to an increasing PKC $\alpha$ expression in pituitary tumors. Finally, overexpression of miR-200b in AtT-20 cells downregulated mRNA and protein expression of $\mathrm{PKC} \alpha$, and exogenous PKC $\alpha$ could reverse this inhibitory effect in AtT-20 cells.

$\mathrm{PKC} \alpha$ belongs to the protein kinase $\mathrm{C}$ family and has been indicated to be involved in tumorigenesis, invasion, metastasis and proliferation (35-37). Previous studies of breast cancer indicated that PKC $\alpha$ could serve as an effective therapeutic target due to its notable mediator role in cancer (38-40). Furthermore, upregulation of PKC $\alpha$ results in cancer cell invasion and proliferation $(36,41,42)$. Therefore, miR-200b interacts with the 3'UTR of PKC $\alpha$ mRNA, affecting the degradation of PKC $\alpha$ mRNA, hindering translation and thus inhibiting pituitary tumor invasion and growth. Notably, the observations of the present study demonstrated that although overexpression of miR-200b and inhibition of PKC $\alpha$ was able to inhibit pituitary tumor cell invasion and growth without a statistically significant difference $(\mathrm{P}>0.05)$, the effect of overexpressing miR-200b was slightly higher than that of inhibiting PKC $\alpha$. However, miR-200b may also target other genes to regulate pituitary tumor growth and metastasis, based on the finding that one miRNA could target multiple target mRNAs $(43,26)$. Additional studies on the details of PKC $\alpha$ function in pituitary tumors are required, including studies on which signaling pathway is involved in promotion of tumor proliferation and invasion. Lastly, miR-200b is an key factor in various cell processes, working via various signaling pathways, including 
the cJun/mitogen-activated protein kinase, p27/kip1 and Rho family GTPase 3 pathways $(44,45)$. It is therefore a potentially fruitful area of research to investigate how miR-200b affects in pituitary tumors.

In conclusion, the expression of miR-200b demonstrated downregulation in pituitary tumors and a negative correlation with PKC $\alpha$ expression. In addition, miR-200b could inhibit pituitary tumor proliferation and invasion and promote tumor cell apoptosis by targeting PKC $\alpha$. PKC $\alpha$ and miR-200b may therefore serve as effective therapeutic targets for pituitary tumor treatment in the future.

\section{References}

1. Gentilin E, Tagliati F, Filieri C, Molè D, Minoia M, Rosaria Ambrosio M, Degli Uberti EC and Zatelli MC: miR-26a plays an important role in cell cycle regulation in ACTH-secreting pituitary adenomas by modulating protein kinase C8. Endocrinology 154: 1690-1700, 2013.

2. D'Angelo D, Palmieri D, Mussnich P, Roche M, Wierinckx A, Raverot G, Fedele M, Croce CM, Trouillas J and Fusco A: Altered microRNA expression profile in human pituitary GH adenomas: Down-regulation of miRNA targeting HMGA1, HMGA2 and E2F1. J Clin Endocrinol Metab 97: E1128-E1138, 2012.

3. Yin Z, Williams-Simons L, Parlow AF, Asa S and Kirschner LS: Pituitary-specific knockout of the Carney complex gene Prkarla leads to pituitary tumorigenesis. Mol Endocrinol 22: 380-387, 2008.

4. Özsu E, Mutlu GY, Çizmecioğlu FM and Hatun Ş: McCune Albright syndrome in association with excessive GH secretion: Case report. Turk Pediatri Ars 50: 114-117, 2015.

5. Lania A and Spada A: G-protein and signalling in pituitary tumours. Horm Res 71 (Suppl 2): S95-S100, 2009.

6. Jiang $X$ and Zhang $X$ : The molecular pathogenesis of pituitary adenomas: An update. Endocrinol Metab (Seoul) 28: 245-254, 2013.

7. Li XH, Wang EL, Zhou HM, Yoshimoto K and Qian ZR: MicroRNAs in human pituitary adenomas. Int J Endocrinol 2014 435171, 2014

8. Calin GA, Sevignani C, Dumitru CD, Hyslop T, Noch E, Yendamuri S, Shimizu M, Rattan S, Bullrich F, Negrini M and Croce CM: Human microRNA genes are frequently located at fragile sites and genomic regions involved in cancers. Proc Natl Acad Sci USA 101: 2999-3004, 2004.

9. Stilling G, Sun Z, Zhang S, Jin L, Righi A, Kovāes G, Korbonits M, Scheithauer BW, Kovacs K and Lloyd RV: MicroRNA expression in ACTH-producing pituitary tumors: up-regulation of microRNA-122 and -493 in pituitary carcinomas. Endocrine 38 67-75, 2010.

10. Butz H, Likó I, Czirják S, Igaz P, Korbonits M, Rácz K and Patócs A: MicroRNA profile indicates downregulation of the TGF $\beta$ pathway in sporadic non-functioning pituitary adenomas Pituitary 14: 112-124, 2011.

11. Qian ZR, Asa SL, Siomi H, Siomi MC, Yoshimoto K, Yamada S, Wang EL, Rahman MM, Inoue H, Itakura M, et al: Overexpression of HMGA2 relates to reduction of the let-7 and its relationship to clinicopathological features in pituitary adenomas. Mod Pathol 22: 431-441, 2009.

12. Mao ZG, He DS, Zhou J, Yao B, Xiao WW, Chen CH, Zhu YH and Wang HJ: Differential expression of microRNAs in GH-secreting pituitary adenomas. Diagn Pathol 5: 79, 2010.

13. Bottoni A, Zatelli MC, Ferracin M, Tagliati F, Piccin D Vignali C, Calin GA, Negrini M, Croce CM and Degli Uberti EC: Identification of differentially expressed microRNAs by microarray: A possible role for microRNA genes in pituitary adenomas. J Cell Physiol 210: 370-377, 2007.

14. Altuvia Y, Landgraf P, Lithwick G, Elefant N, Pfeffer S, Aravin A, Brownstein MJ, Tuschl T and Margalit H: Clustering and conservation patterns of human microRNAs. Nucleic Acids Res 33: 2697-2706, 2005.

15. Korpal M, Lee ES, Hu G and Kang Y: The miR-200 family inhibits epithelial-mesenchymal transition and cancer cell migration by direct targeting of E-cadherin transcriptional repressors ZEB1 and ZEB2. J Biol Chem 283: 14910-14914, 2008.
16. Burk U, Schubert J, Wellner U, Schmalhofer O, Vincan E, Spaderna $\mathrm{S}$ and Brabletz T: A reciprocal repression between ZEB1 and members of the miR-200 family promotes EMT and invasion in cancer cells. EMBO Rep 9: 582-589, 2008.

17. Leskela S, Leandro-García LJ, Mendiola M, Barriuso J, Inglada-Pérez L, Muñoz I, Martínez-Delgado B, Redondo A, de Santiago J, Robledo M, et al: The miR-200 family controls beta-tubulin III expression and is associated with paclitaxel-based treatment response and progression-free survival in ovarian cancer patients. Endocr Relat Cancer 18: 85-95, 2011.

18. Xia W, Li J, Chen L, Huang B, Li S, Yang G, Ding H, Wang F, Liu N, Zhao Q, et al: MicroRNA-200b regulates cyclin D1 expression and promotes S-phase entry by targeting RND3 in HeLa cells. Mol Cell Biochem 344: 261-266, 2010.

19. Basu A and Sivaprasad U: Protein kinase Cepsilon makes the life and death decision. Cell Signal 19: 1633-1642, 2007.

20. Petiti JP, Gutiérrez S, De Paul AL, Andreoli V, CM, Sosa Ldel V, Bocco JL and Torres AI: GH3B6 pituitary tumor cell proliferation is mediated by PKCalpha and PKCepsilon via ERK 1/2-dependent pathway. Cell Physiol Biochem 26: 135-146, 2010.

21. Hardy $\mathbf{J}$ and Vezina JL: Transsphenoidal neurosurgery of intracranial neoplasm. Adv Neurol 15: 261-273, 1976.

22. Knosp E, Steiner E, Kitz K and Matula C: Pituitary adenomas with invasion of the cavernous sinus space: A magnetic resonance imaging classification compared with surgical findings. Neurosurgery 33: 610-618, 1993.

23. Livak KJ and Schmittgen TD: Analysis of relative gene expression data using real-time quantitative PCR and the 2(-Delta Delta C(T)) Method. Methods 25: 402-408, 2001.

24. Zhao A, Zeng Q, Xie X, Zhou J, Yue W, Li Y and Pei X: MicroRNA-125b induces cancer cell apoptosis through suppression of Bcl-2 expression. J Genet Genomics 39: 29-35, 2012.

25. Hu X, Xin Y, Xiao Y and Zhao J: Overexpression of YAP1 is correlated with progression, metastasis and poor prognosis in patients with gastric carcinoma. Pathol Oncol Res 20: 805-811, 2014.

26. He L and Hannon GJ: MicroRNAs: Small RNAs with a big role in gene regulation. Nat Rev Genet 5: 522-531, 2004.

27. Lu J, Getz G, Miska EA, Alvarez-Saavedra E, Lamb J, Peck D, Sweet-Cordero A, Ebert BL, Mak RH, Ferrando AA, et al: MicroRNA expression profiles classify human cancers. Nature 435: 834-838, 2005.

28. Fabian MR, Sonenberg N and Filipowicz W: Regulation of mRNA translation and stability by microRNAs. Annu Rev Biochem 79: 351-379, 2010.

29. McManus MT: MicroRNAs and cancer. Semin Cancer Biol 13: 253-258, 2003

30. Muralidhar GG and Barbolina MV: The miR-200 Family: Versatile players in epithelial ovarian cancer. Int J Mol Sci 16: $16833-16847,2015$

31. Chang L, Guo F, Huo B, Lv Y, Wang Y and Liu W: Expression and clinical significance of the microRNA-200 family in gastric cancer. Oncol Lett 9: 2317-2324, 2015.

32. Bracken CP, Khew-Goodall Y and Goodall GJ: Network-Based Approaches to Understand the Roles of miR-200 and Other microRNAs in Cancer. Cancer Res 75: 2594-2599, 2015

33. Liu W, Qi L, Lv H, Zu X, Chen M, Wang J, Liu L, Zeng F and Li Y: MiRNA-141 and miRNA-200b are closely related to invasive ability and considered as decision-making biomarkers for the extent of PLND during cystectomy. BMC Cancer 15: 92, 2015.

34. Kurashige J, Kamohara H, Watanabe M, Hiyoshi Y, Iwatsuki M, Tanaka Y, Kinoshita K, Saito S, Baba Y and Baba H: MicroRNA-200b regulates cell proliferation, invasion, and migration by directly targeting ZEB2 in gastric carcinoma. Ann Surg Oncol 19 (Suppl 3): S656-S664, 2012.

35. Yue CH, Huang CY, Tsai JH, Hsu CW, Hsieh YH, Lin $\mathrm{H}$ and Liu JY: MZF-1/Elk-1 Complex Binds to Protein Kinase Ca Promoter and Is Involved in Hepatocellular Carcinoma. PLoS One 10: e0127420, 2015.

36. Chen H, Yu Y, Rong S and Wang H: Evaluation of diagnostic accuracy of DNA methylation biomarkers for bladder cancer: A systematic review and meta-analysis. Biomarkers 19: 189-197, 2014.

37. Hsu YH, Yao J, Chan LC, Wu TJ, Hsu JL, Fang YF, Wei Y, Wu Y, Huang WC, Liu CL, et al: Definition of PKC- $\alpha$, CDK6, and MET as therapeutic targets in triple-negative breast cancer. Cancer Res 74: 4822-4835, 2014.

38. Humphries B, Wang Z, Oom AL, Fisher T, Tan D, Cui Y, Jiang Y and Yang C: MicroRNA-200b targets protein kinase $\mathrm{C} \alpha$ and suppresses triple-negative breast cancer metastasis. Carcinogenesis 35: 2254-2263, 2014. 
39. Sliva D, English D, Lyons D and Lloyd FP Jr: Protein kinase $\mathrm{C}$ induces motility of breast cancers by upregulating secretion of urokinase-type plasminogen activator through activation of AP-1 and NF-kappaB. Biochem Biophys Res Commun 290: 552-557, 2002.

40. Tam WL, Lu H, Buikhuisen J, Soh BS, Lim E, Reinhardt F, $\mathrm{Wu}$ ZJ, Krall JA, Bierie B, Guo W, et al: Protein kinase C $\alpha$ is a central signaling node and therapeutic target for breast cancer stem cells. Cancer Cell 24: 347-364, 2013.

41. Konopatskaya O and Poole AW: Protein kinase Calpha: Disease regulator and therapeutic target. Trends Pharmacol Sci 31: 8-14, 2010.

42. Urtreger AJ, Kazanietz MG and Bal de Kier Joffé ED: Contribution of individual PKC isoforms to breast cancer progression. IUBMB Life 64: 18-26, 2012.
43. Vrba L, Garbe JC, Stampfer MR and Futscher BW: Epigenetic regulation of normal human mammary cell type-specific miRNAs. Genome Res 21: 2026-2037, 2011.

44. Jadhav SP, Kamath SP, Choolani M, Lu J and Dheen ST: microRNA-200b modulates microglia-mediated neuroinflammation via the cJun/MAPK pathway. J Neurochem 130: 388-401, 2014.

45. Tong J, Fu Y, Xu X, Fan S, Sun H, Liang Y, Xu K, Yuan Z and Ge Y: TGF- $\beta 1$ stimulates human Tenon's capsule fibroblast proliferation by miR-200b and its targeting of p27/kip1 and RND3. Invest Ophthalmol Vis Sci 55: 2747-2756, 2014. 